\title{
ENTONACIÓN DE CORTESÍA INVOLUNTARIA EN EL ESPAÑOL HABLADO POR BRASILEÑOS
}

\author{
Empar Devís Herraiz \\ Universidad de Barcelona \\ devis@ub.edu
}

\begin{abstract}
Resumen
El objetivo del presente trabajo es reflejar cómo los rasgos melódicos del español hablado por brasileños, por su semejanza con los identificados como rasgos corteses en español, provocan que un brasileño fácilmente sea interpretado como un hablante cortés, simpático y afable cuando se encuentra con un hablante español, pues su entonación prelingüística contiene una gran cantidad de rasgos identificados como corteses atenuadores en español.
\end{abstract}

Palabras clave: entonación, cortesía involuntaria, español lengua extranjera

\section{Resum}

L'objectiu del present treball és reflexar com els trets melòdics de l'espanyol parlat per brasilers, per la seva semblança amb els identificats com a trets cortesos en espanyol, provoquen que un brasiler fàcilment sigui interpretat com un parlant cortès, simpàtic i afable quan es troba amb un parlant espanyol, doncs la seva entonació prelingüística compté una gran quantitat de trets identificats com a cortesos atenuadors en espanyol.

Paraules clau: entonació, cortesia involuntària, espanyol llengua estrangera

\begin{abstract}
The aim of the present work is to reflect how the melodic features of spanish spoken by brazilians, by their resemblance to those identified as polite features in spanish, provoke a brazilian to be easily interpreted as a polite, sympathetic and affable speaker when he meets a speaker spanish, because its prelinguistic intonation contains a great number of traits identified as politeness in spanish.
\end{abstract}

Keywords: intonation, involuntary politeness, spanish foreign language

\section{INTRODUCCIÓN}

La entonación es un factor decisivo en la pronunciación de las lenguas extranjeras porque funciona como organizador del discurso oral. Una entonación adecuada favorece, por tanto, la compresión de un discurso y posibilita una comunicación fluida entre hablantes de distintos idiomas.

El español hablado por brasileños se caracteriza por un discurso codificado (gramaticalmente) en la lengua meta, pero organizado según la entonación propia del 
portugués: el resultado es un estilo de habla que, como veremos, puede dificultar la comunicación con los nativos de español, provocando malentendidos muy negativos en ciertas situaciones comunicativas.

En los estudios sobre adquisición fónica de lenguas extranjeras, la entonación ha sido un elemento tradicionalmente descuidado, y aun ahora es uno de los ámbitos de estudio en los que se solicita más investigación. Lo mismo pasa en el ámbito de estudio de la entonación de cortesía y descortesía en un idioma. Sabemos que la expresión de cortesía en el diálogo cotidiano es un efecto habitualmente expresado a través de los recursos fónicos en general y suprasegmentales en particular. Junto a los mecanismos de índole morfológica, sintáctica, léxica, semántica, etc., también la participación del componente fónico debe ser tenida en cuenta; sin embrago, los estudios con los que contamos siguen siendo abrumadoramente escasos.

El presente trabajo, pues, pretende subsanar la ausencia de estudios exhaustivos que aporten un volumen amplio de datos en estos dos ámbitos de estudio. Para ello, ahondaremos en la caracterización de los principales rasgos melódicos del español hablado por brasileños (Fonseca \& Cantero: 2011) y abordaremos la delimitación de los rasgos melódicos de cortesía, conducentes a la creación de efectos contextuales atenuadores en español coloquial (Devís: 2011) ${ }^{1}$.

Nuestro objetivo es reflejar cómo los rasgos melódicos del español hablado por brasileños, por su semejanza con los identificados como rasgos corteses en español, provocan que un brasileño fácilmente sea interpretado como un hablante cortés, simpático y afable cuando se encuentra con un hablante español, pues su entonación prelingüística $^{2}$ contiene una gran cantidad de rasgos identificados como corteses atenuadores en español. Esta situación no se percibe como negativa en la mayor parte de los casos, pero pueden darse situaciones contextuales de mayor exigencia y formalidad, como en una reunión de negocios o en una reunión académica, donde sí que podría interpretarse como una entonación inadecuada. En estas situaciones, los brasileños son percibidos como hablantes poco serios y poco creíbles, provocando un malentendido muy negativo para que la comunicación entre hablantes de estos dos idiomas resulte feliz y eficaz. La caracterización y comparación de estos rasgos melódicos resulta, por tanto, de suma importancia, sobre todo para aquellos hablantes brasileños que quieran aprender el español con fines profesionales.

\section{METODOLOGÍA}

Para el análisis de los datos se ha aplicado, en ambos estudios, el método de análisis melódico del habla que presenta F.J. Cantero (2002) en su libro Teoría y Análisis de la entonación. El punto de partida es la definición de la entonación a partir de las variaciones de F0 que cumplen una función lingüística a lo largo de la emisión de voz (Cantero, 2002: 18). El autor considera que la entonación funciona en tres niveles:

\footnotetext{
${ }^{1}$ La investigación se sitúa dentro del Proyecto "Fonocortesía: el componente fónico en la expresión de cortesía y descortesía verbales en español coloquial”. Referencia: FFI2009-07034. Proyecto del MICINN (Ministerio de Ciencia e Innovación de España).

${ }^{2}$ Por nivel prelingüístico nos referimos al primer nivel de entonación descrito por Cantero (2002).
} 
- Pre-lingüístico: Comprende los fenómenos del acento, el ritmo y la melodía, que funcionan solidariamente como elementos fónicos coestructuradores del discurso, al margen de cualquier otra dimensión significativa.

En este nivel, se considera la entonación como un “contenedor” lingüístico, integrando y delimitando las unidades del discurso. Es lo que Quilis (1993) llamaba "función delimitadora” y "función integradora” de la entonación. Los rasgos melódicos característicos de este nivel son rasgos fonéticos, bien concretos.

- Lingüístico: Comprende las características melódicas cuyo rendimiento fonológico permite caracterizar y distinguir las unidades funcionales de la entonación, sus "signos lingüísticos".

En español fueron identificados ocho tonemas resultantes de la combinación de los rasgos fonológicos ${ }^{3}$ (/ \pm interrogativa, \pm suspendida, \pm enfática/) que conforman los 4 tipos de entonación descritos por el autor (neutra, interrogativa, suspendida y enfática), cuyos patrones melódicos constituyen las melodías típicas del español (v. Cantero \& Font-Rotchés, 2007).Hasta el día de hoy se han encontrado doce patrones melódicos diferentes para el español, con sus variantes y márgenes de dispersión.

- Paralingüístico: comprende las variantes melódicas de tales tonemas, dentro de los amplios márgenes de dispersión de cada uno de ellos.

Tales melodías permiten expresar emociones particulares, rasgos discursivos idiolectales o de la personalidad del hablante, e incluso pueden estar variablemente codificadas (como ocurre, por ejemplo, en la expresión de la "cortesía”: v. Devís: 2011).

El método para el análisis de los tres niveles de entonación permite:

- segmentar la curva entonativa en segmentos tonales (normalmente, un segmento tonal por vocal, excepto en las inflexiones);

- $\quad$ analizar la entonación independiente de otros niveles de análisis lingüístico;

- analizar todos los fenómenos tonales del habla incluidos en la melodía (acento, ritmo y entonación).

Y comprende dos fases:

\section{Fase acústica (descriptiva):}

- $\quad$ extracción de la F0 del enunciado;

- $\quad$ determinación de los valores de F0 vocálicos. Se identifican las vocales y se anota su valor medio;

- la sucesión de valores vocálicos genera una curva melódica esencial que elimina los valores irrelevantes;

- $\quad$ y, en último lugar, cada patrón melódico obtenido en $\mathrm{Hz}$ se estandariza en porcentajes para construir una melodía independiente de las características del hablante.

\footnotetext{
${ }^{3}$ Los rasgos fonológicos descritos en este nivel son rasgos abstractos, meramente opositivos.
} 
Fase perceptiva (experimental):

- $\quad$ se sintetiza la melodía resultante mediante el programa de análisis acústico PRAAT y se substituyen los valores tonales por los valores estandarizados;

- $\quad$ se modifican únicamente los valores cuya relevancia queremos comprobar;

- $\quad$ se realiza un experimento perceptivo que permita validar la melodía sintetizada y/o falsar la hipótesis melódica.

\section{CORPUS}

\subsection{Corpus de español hablado por brasileños}

Para el estudio de la entonación del español hablado por brasileños (Fonseca \& Cantero: 2011) optaron por la realización de grabaciones de habla espontánea, por considerar que era la manera más fiable de averiguar y conocer la interlengua fónica de los informantes, dado que de esta manera se evita la influencia, consciente o inconsciente de la lengua escrita. Los datos fueron únicamente analizados acústicamente, la fase perceptiva está pendiente de realización.

\subsection{Corpus VaL.Es.Co}

Val.Es.Co. (Valencia, Español Coloquial) ${ }^{4}$ constituye un grupo de investigación surgido en el seno del Departamento de Filología Española de la Universidad de Valencia en 1990. Su principal objeto de estudio fue desde el principio el español coloquial. Val.Es.Co. ha venido abordando la descripción y explicación del llamado español coloquial en sus distintos niveles de análisis a partir de un corpus oral, obtenido directamente de la conversación espontánea. La hipótesis inicial era que el funcionamiento de la conversación coloquial podía explicarse, no como transgresión de la gramática oracional, sino como conjunto de estructuras y estrategias, de base pragmática, constituidas en el proceso de interacción.

\section{ENTONACIÓN PRELINGÜÍSTICA DEL ESPAÑOL HABLADO POR BRASILEÑOS}

Presentamos a continuación algunos de los ejemplos analizados siguiendo el método de análisis melódica del habla (Fonseca \& Cantero, 2011: 5). En general no se observa la presencia del primer pico. El primer pico indica, en español, la marca de un grupo fónico (suele ser la primera vocal tónica del enunciado). Esto indica una tendencia a organizar los grupos fónicos de manera distinta a como ocurre en español. Cuando hay indicios de primeros picos estos suelen ocurrir en la pretónica o en la postónica.

Al no existir primer pico, tampoco hay declinación. Por lo que nos encontramos con melodías muy planas que, sin embargo, presentan en su un interior una gran cantidad de inflexiones internas y de prominencias en átonas. Estos son los dos rasgos melódicos que seguramente marquen la entonación prelingüística del español hablado por

\footnotetext{
${ }^{4}$ Ver http://www.valesco.es/
} 
brasileños y que, como veremos más adelante, serán también los que determinen la entonación de cortesía atenuadora en el español coloquial.

Como resultado de esta entonación prelingüística, la organización del discurso es en parte extraña al español estándar, pero no lo es al español coloquial con función cortés.

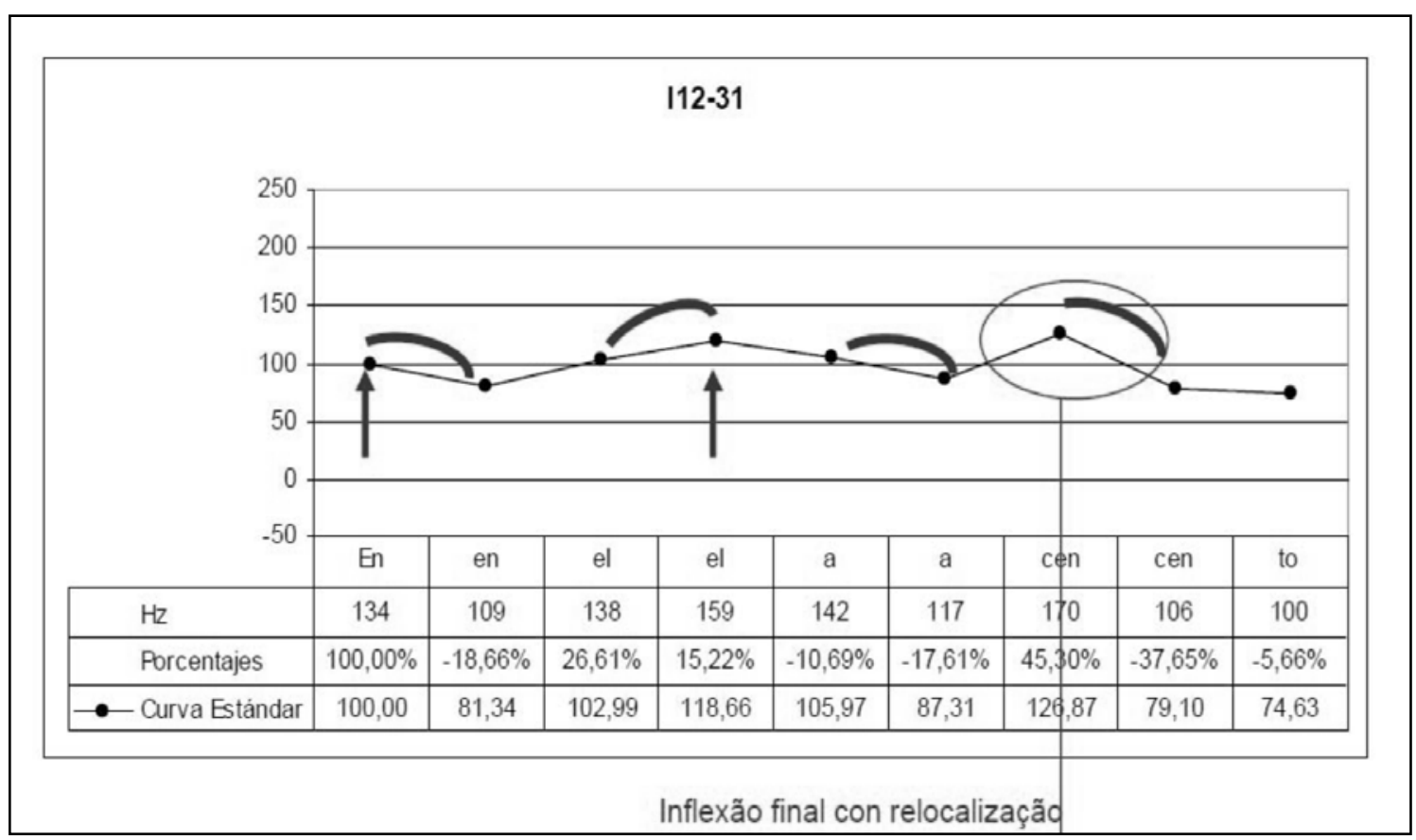

Figura1. Melodía estandarizada del enunciado: "En el acento"

La figura 1 presenta un grupo fónico con una serie de inflexiones internas y de prominencias en vocales átonas. Los dos rasgos melódicos principales que caracterizan la entonación prelingüística del español hablado por brasileños.

El método de Análisis melódico del habla trabaja siempre a partir de curvas estandarizadas porque sólo la relativización de cada valor tonal con respecto al valor anterior permite construir la melodía tal cual es, independientemente de las características del hablante, y para relativizar utiliza los porcentajes por la dificultad que presenta trabajar con semitonos o decimales.

Cada punto de la curva es un valor vocálico representativo. En el análisis melódico interesan solo los valores vocálicos puesto que el sonido más importante del discurso siempre es la vocal. Cada valor vocálico constituye un segmento tonal de la melodía que suele corresponder a la sílaba (en el gráfico los vemos segmentados por columnas). Sólo en los casos en los que la duración de la vocal es significativa mente mayor (no una sino dos moras de duración), podemos suponer que la vocal constituye no uno sino dos segmentos tonales: en tales casos, la vocal contiene un inflexión tonal, que se define, precisamente, como la sucesión de dos (o más) segmentos tonales en una vocal (en esta primera figura observamos cuatro inflexiones internas con dos segmentos tonales). Segmento tonal, por tanto, es cada valor de F0 relevante en la melodía, consideramos que hay dos segmentos tonales cuando el porcentaje de ascenso o de descenso es igual o superior al $10 \%^{5}$.

\footnotetext{
${ }^{5}$ Veasé Cantero (1999).
} 
En la primera línea horizontal observamos los valores en Herz (valores absolutos obtenidos a partir de las vocales), en la segunda observamos los porcentajes de ascenso y de descenso. El primer valor es 100\% -número arbitrario también podría haber sido 0a partir del cual se anotan los tantos por cien de desnivel entre un segmento y el siguiente obteniendo los valores relativos, la última línea muestra los valores de la curva estandariza a partir de los porcentajes de ascenso y de descenso. Cada gráfico muestra la representación de esta curva estándar.

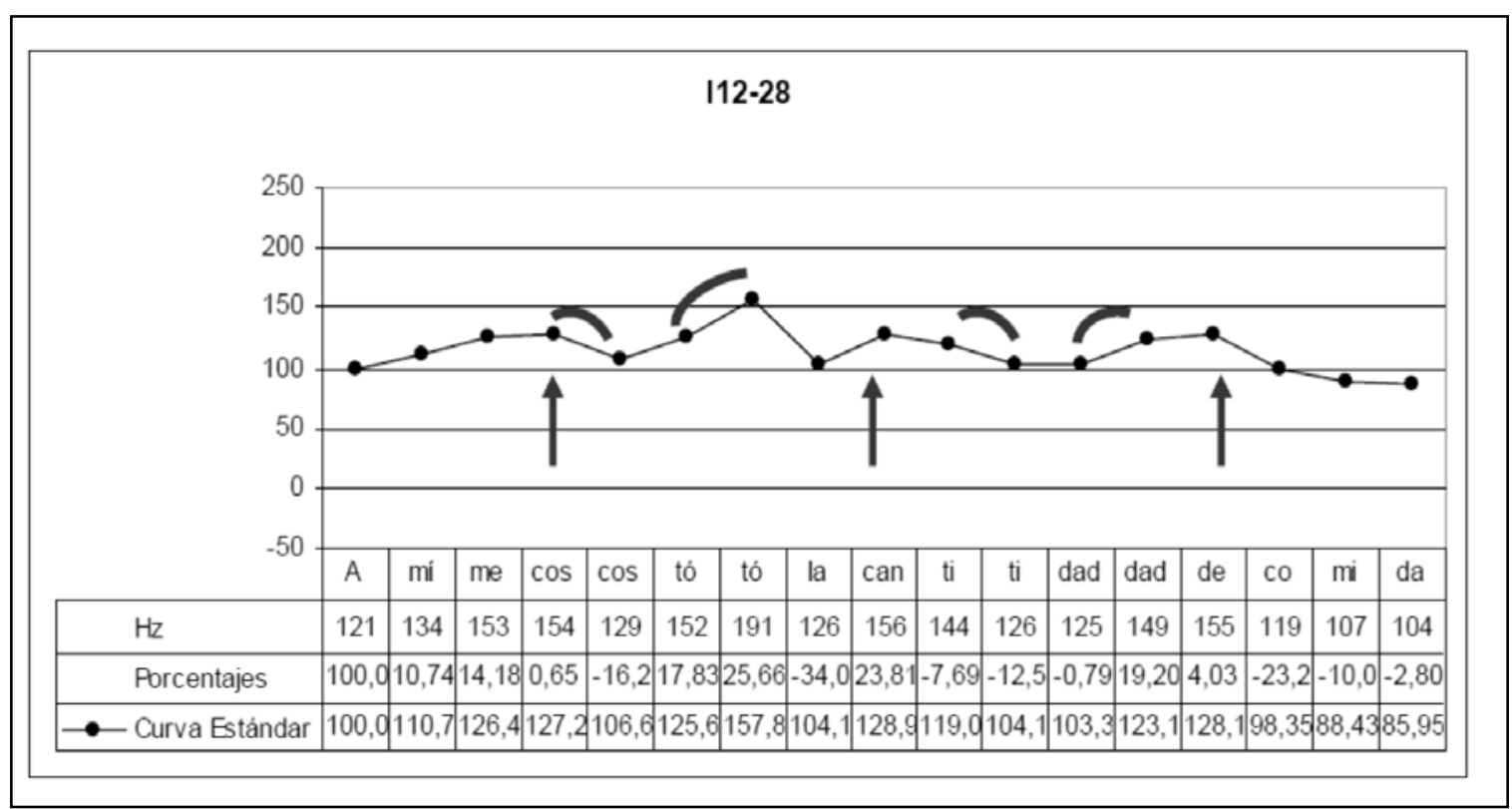

Figura 2. Melodía estandarizada del enunciado: “A mí me costó la cantidad de comida”

En la figura 2 aparecen los mismos rasgos melódicos descritos.

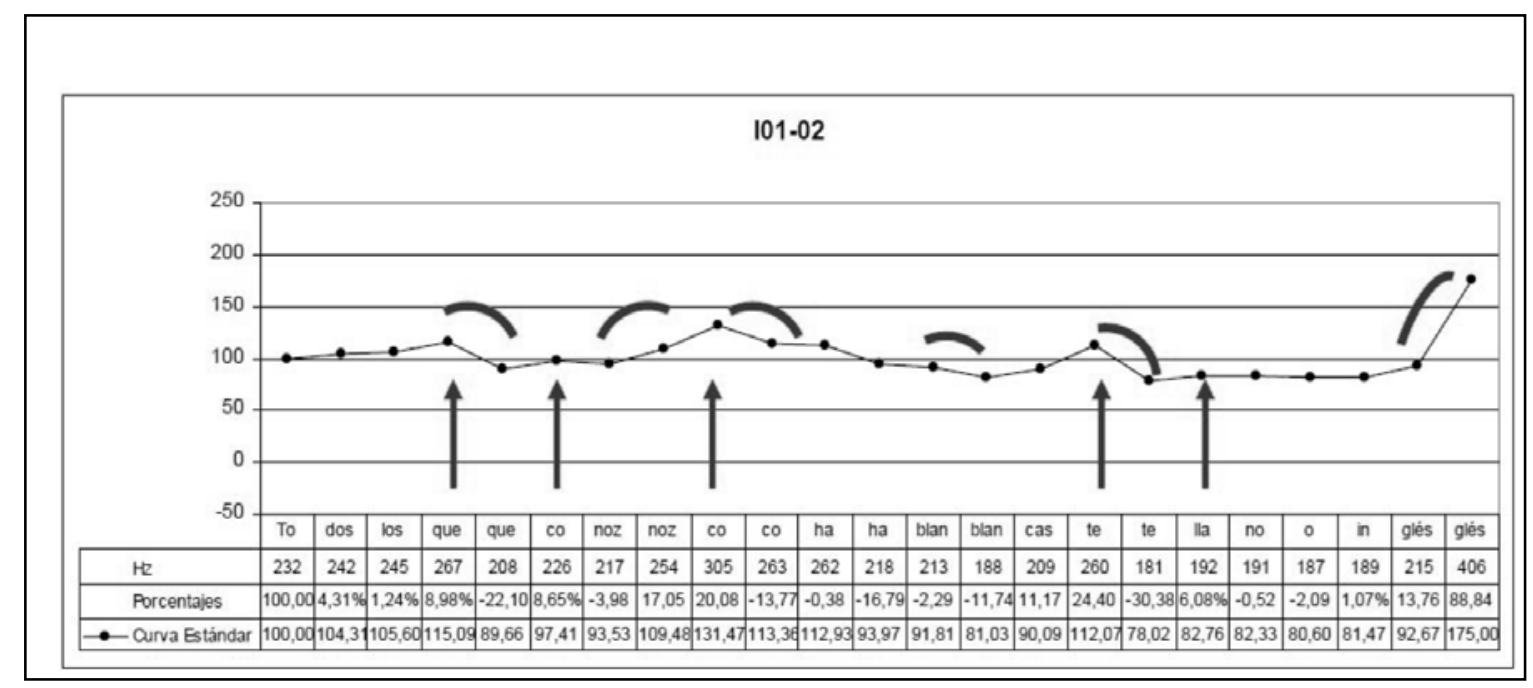

Figura 3. Melodía estandarizada del enunciado: “Todos los que conozco hablan castellano o inglés”

Como podemos observar en la figura 3 las inflexiones internas y las prominencias en átonas son recurrentes en el español hablado por brasileños. 


\section{ENTONACIÓN DE CORTESÍA ATENUADORA DEL ESPAÑOL COLOQUIAL}

\subsection{Fase acústica}

Presentamos a continuación algunos ejemplos del corpus VALESCO_084.A1 de donde fueron extraídos los principales rasgos melódicos atenuadores del español coloquial, algunos de ellos, los más relevantes (inflexiones internas y prominencias en átonas), coincidentes con los identificados en el español hablado por brasileños.

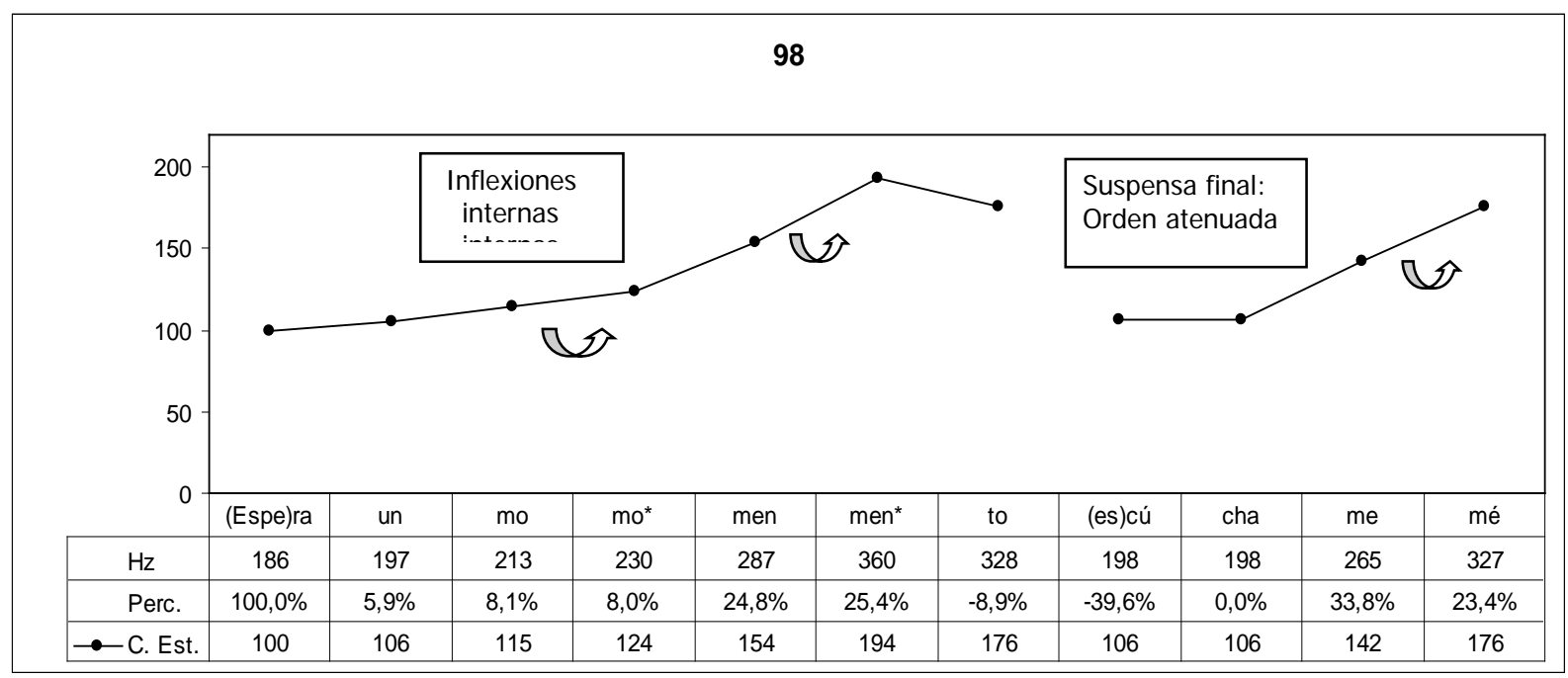

Figura 4. Melodía estandarizada del enunciado: "Espera un momento, escúchame”

La figura 4 presenta dos grupos fónicos. Las inflexiones internas, en este caso, desde el punto de vista de la entonación paralingüística ${ }^{6}$, se convierten en claves acústicas relevantes para distinguir un enunciado cortés de uno neutro, son énfasis de foco ancho muy recurrentes en todos los ejemplos analizados generando un ritmo melódico que distingue y caracteriza las emisiones corteses atenuadoras.

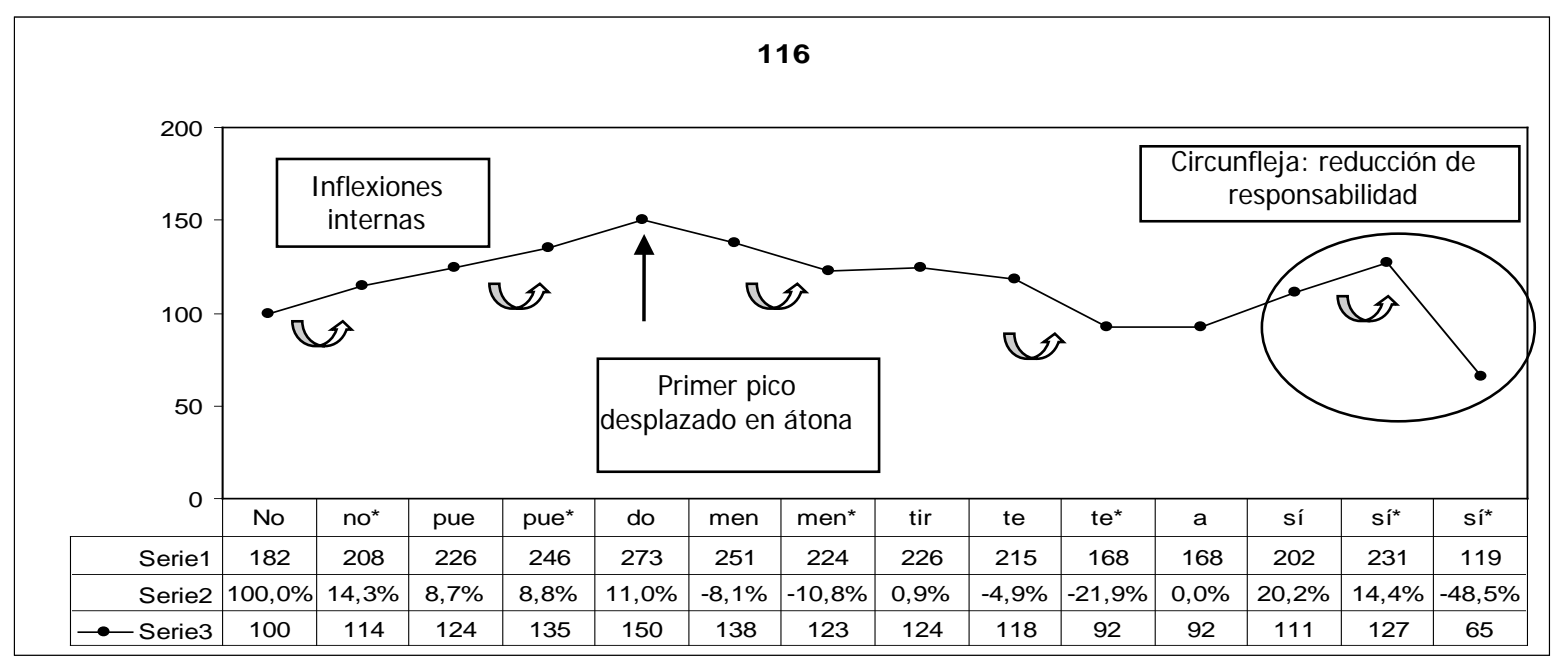

Figura 5. Melodía estandarizada del enunciado: "No puedo mentirte así”

\footnotetext{
${ }^{6}$ El nivel paralingüístico es el tercer nivel de entonación descrito por Cantero (2002).
} 
La figura 5 presenta un grupo fónico con el primer pico desplazado (como ocurre también en el español hablado por brasileños), y una serie de inflexiones internas.

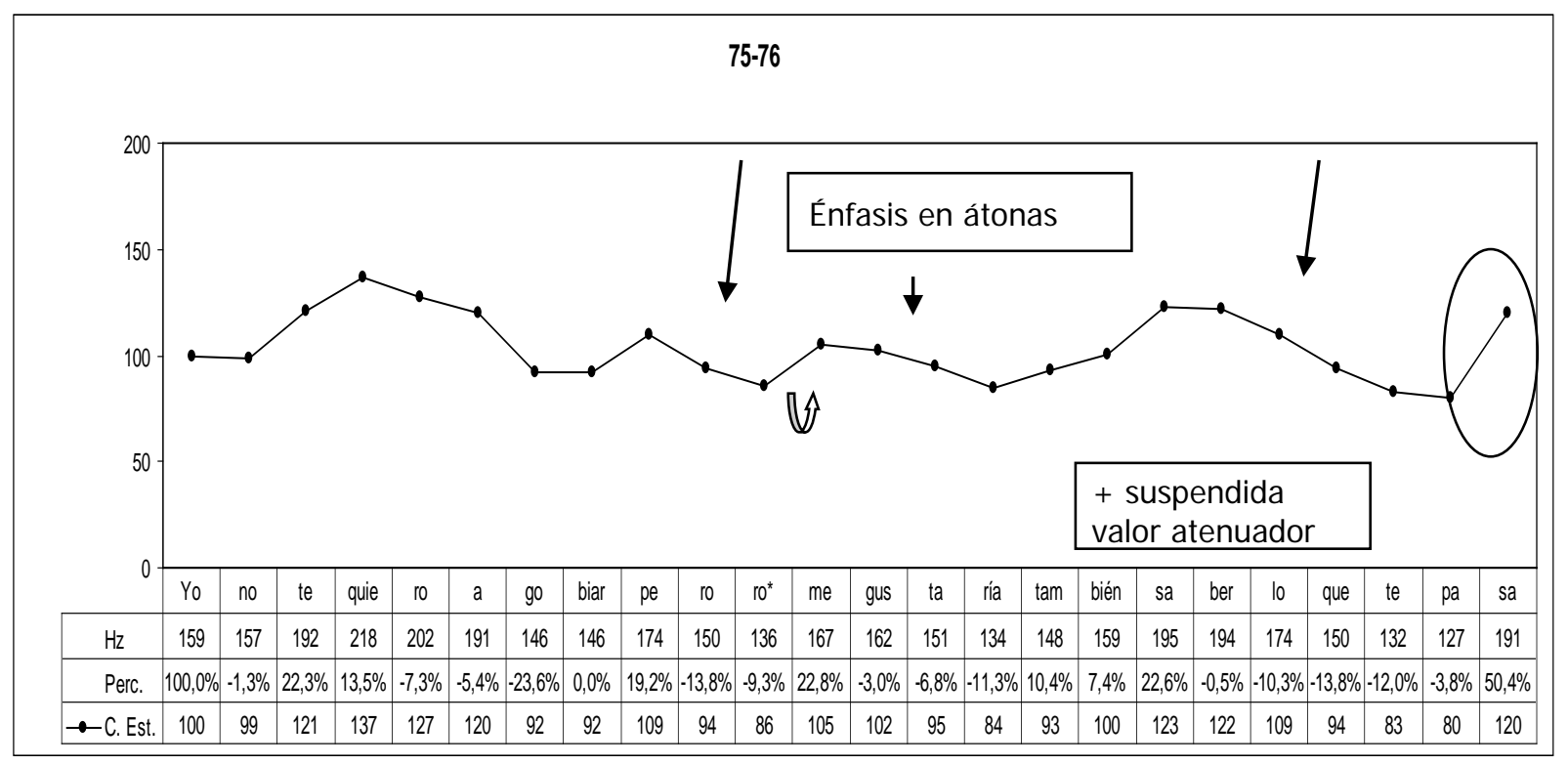

Figura 6. Melodía estandarizada del enunciado: "Yo no quiero agobiarte pero me gustaría saber lo que te pasa”

La figura 6 muestra otra clave acústica, situada también en el nivel de entonación paralingüística, relevante para distinguir un enunciado cortés de uno neutro, en este caso son los énfasis de foco ancho en vocales átonas (o prominencias en átonas), recurrente en todos nuestros ejemplos como ocurría también en el español hablado por brasileños.

Los datos analizados permitieron elaborar la siguiente hipótesis sobre los rasgos melódicos responsables de mitigar enunciados que podrían contener algún tipo de “agresividad” léxico-gramatical implícita. Estos rasgos son:

1) Desde el punto de vista de la entonación lingüística.

\begin{tabular}{|c|}
\hline Inflexiones finales \\
\hline + suspendida: \\
(con ascenso final entre el 15 y el 70\%) \\
\hline + interrogativa \\
\hline + enfática circunfleja: asc-desc; desc-asc. \\
\hline
\end{tabular}

2) Desde el punto de vista de la entonación paralingüística.

\begin{tabular}{|c|}
\hline $\begin{array}{c}\text { Rasgos de énfasis } \\
\text { (foco ancho) }\end{array}$ \\
\hline Prominencia en átonas \\
\hline Inflexiones internas \\
\hline Registro tonal bajo \\
\hline Primer pico desplazado o ausente \\
\hline
\end{tabular}

${ }^{7}$ En negrita, los rasgos coincidentes con la entonación prelingüística del español hablado por brasileños. 


\begin{tabular}{|c|}
\hline $\begin{array}{c}\text { Rasgos de énfasis de palabra } \\
\text { (foco estrecho) }\end{array}$ \\
\hline Énfasis de palabra con inflexión circunfleja \\
\hline Énfasis de palabra con inflexión \\
+ interrogativa
\end{tabular}

Esta amplia clasificación fue el punto de partida para elaborar la fase perceptiva y poder validar las hipótesis de la fase acústica.

\subsection{Fase perceptiva}

El corpus para la fase perceptiva fue creado ad hoc para poder asegurar que los originales eran, claramente, enunciados descorteses, desde el punto de vista léxicogramatical, y que los rasgos, exclusivamente melódicos, introducidos en las manipulaciones eran los únicos responsables de aportar atenuación. Para ello, se grabaron 4 insultos, 4 órdenes y 6 confrontaciones producidos por un hombre y una mujer de los cuales seleccionamos 15 (8 de mujer y 7 de hombre) para su manipulación.

En primer lugar manipulamos solo las inflexiones finales, creando un total de 45 versiones, 3 por cada uno de los 15 enunciados originales seleccionados. En segundo lugar manipulamos solo algún rasgo interno (o las prominencias en átonas, o la F0 baja o el énfasis de palabra) dejando el resto del enunciado original y creando un total de 15 versiones más. En último lugar, procedimos a las manipulaciones combinadas. Escogimos un enunciado que contenía la manipulación de un rasgo interno y le añadimos una inflexión final diferente a la original (interrogativa, circunfleja o suspensa) creando un total de 11 versiones combinadas.

Entre todas las versiones contamos con 71 versiones manipuladas. Posteriormente, elaboramos tres tests perceptivos: uno para 27 oyentes, otro para 26 y el último para 24. En cada test ofrecimos los 15 enunciados originales y seleccionamos una versión manipulada de cada original para cada uno de los tests. De este modo pudimos validar 45 de las 71 versiones manipuladas. La fase perceptiva ofrecía, por tanto, a los 77 oyentes seleccionados, divididos en tres grupos, 15 enunciados originales y una versión manipulada por cada original.

Mostramos a continuación dos ejemplos de enunciados originales con sus respectivas manipulaciones:

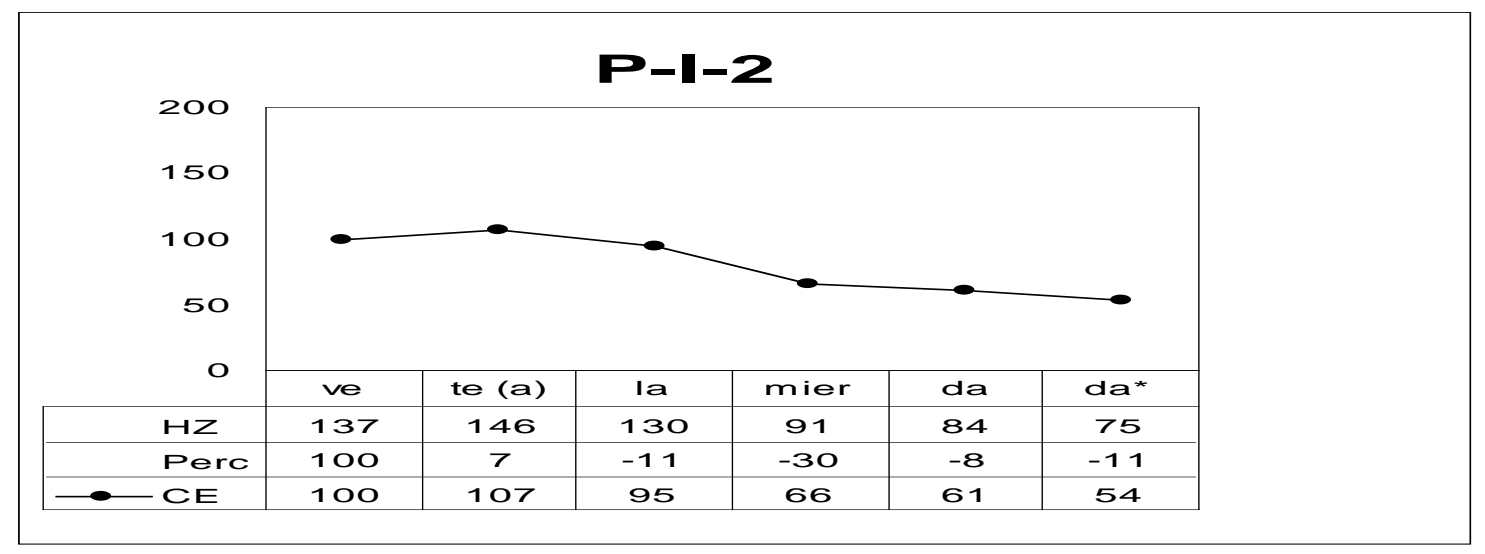

Figura 7. Enunciado original estandarizado del insulto "vete a la mierda" 
La figura 7 muestra uno de los enunciados creados ad hoc para su posterior manipulación. En la segunda columna ponemos la “a” entre paréntesis porque la "e” de "te" y la "a” tienen el mismo valor.

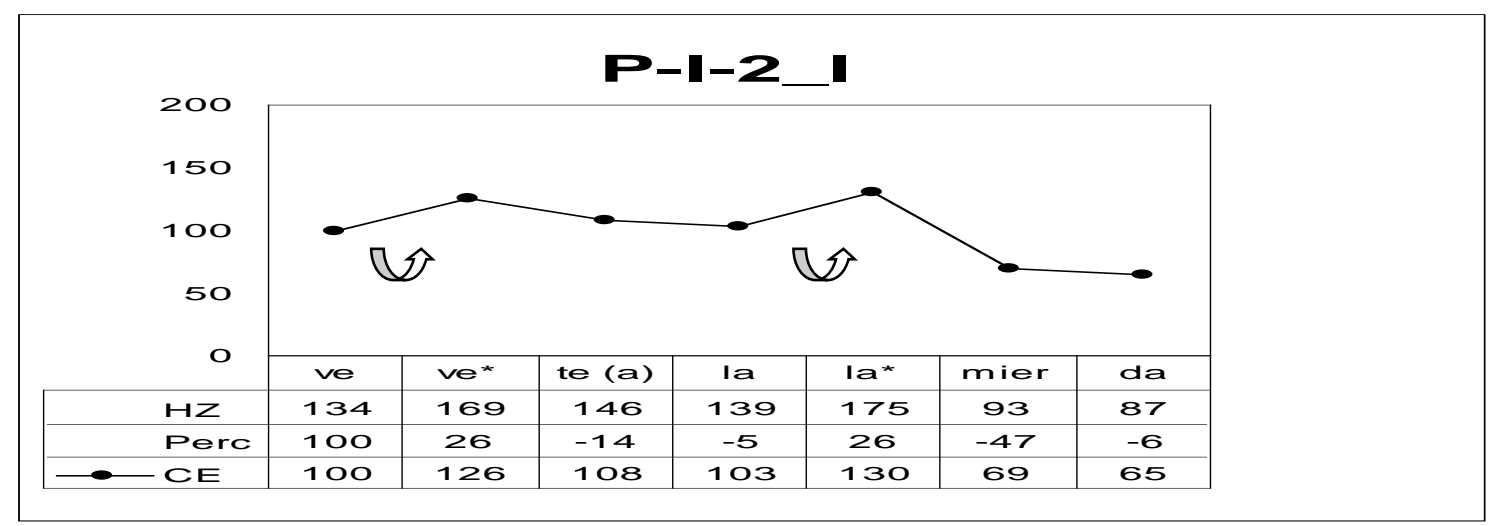

Figura 8. Manipulación del mismo enunciado con inflexiones internas

La figura 8 muestra la manipulación del anterior enunciado original incorporando dos inflexiones internas ascendentes en el primer y tercer segmento tonal. Cada segmento tonal desdoblado se transcribe con un asterisco.

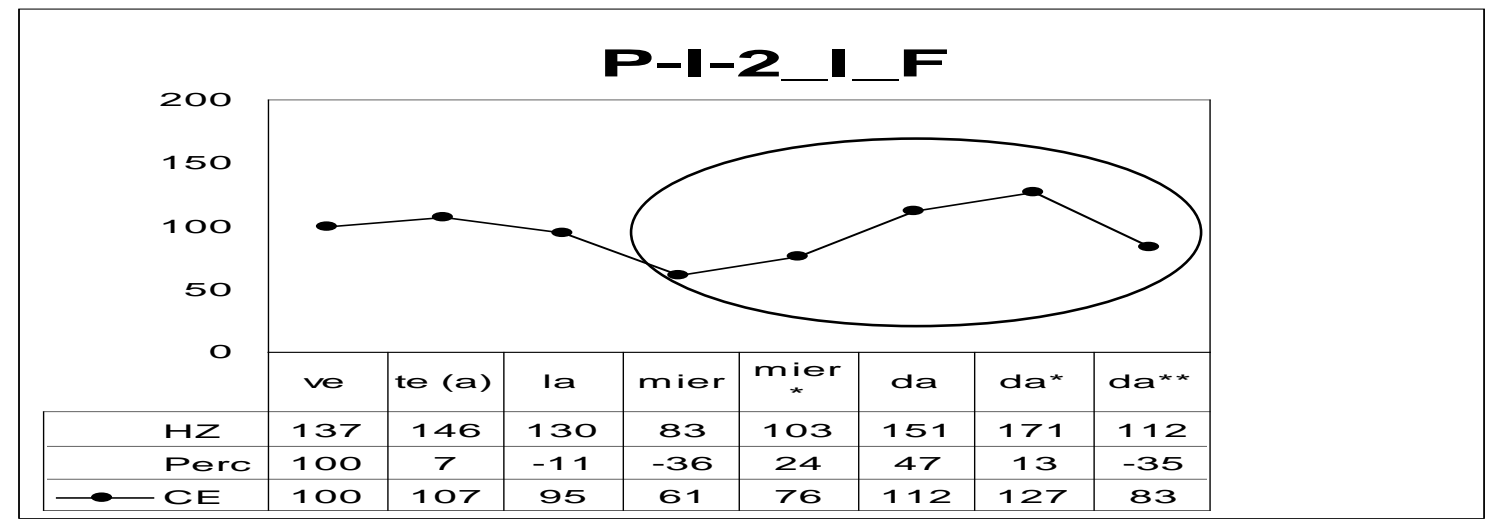

Figura 9. Manipulación del mismo enunciado con inflexión final circunfleja

La figura 9 muestra la manipulación del mismo enunciado original incorporando solo una inflexión final circunfleja y dejando el resto del enunciado original. La inflexión final empieza en la última vocal tónica hasta el final del enunciado. Podemos observar la última vocal átona con tres segmentos tonales para ello hemos utilizado en la última columna dos asteriscos. 


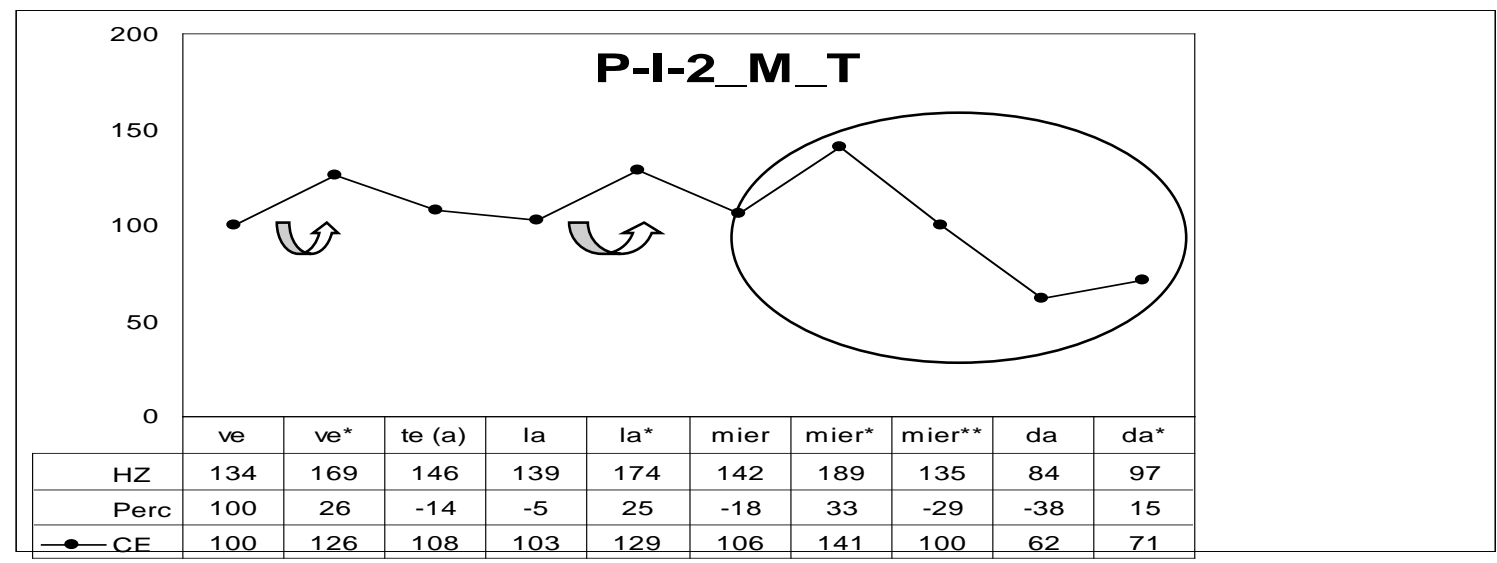

Figura 10. Manipulación del mismo enunciado con inflexiones internas más inflexión final circunfleja

La figura 10 muestra una manipulación combinada del mismo enunciado original. Como se puede observar se han introducido las inflexiones internas ascendentes en el primer y tercer segmento tonal y la inflexión final circunfleja.

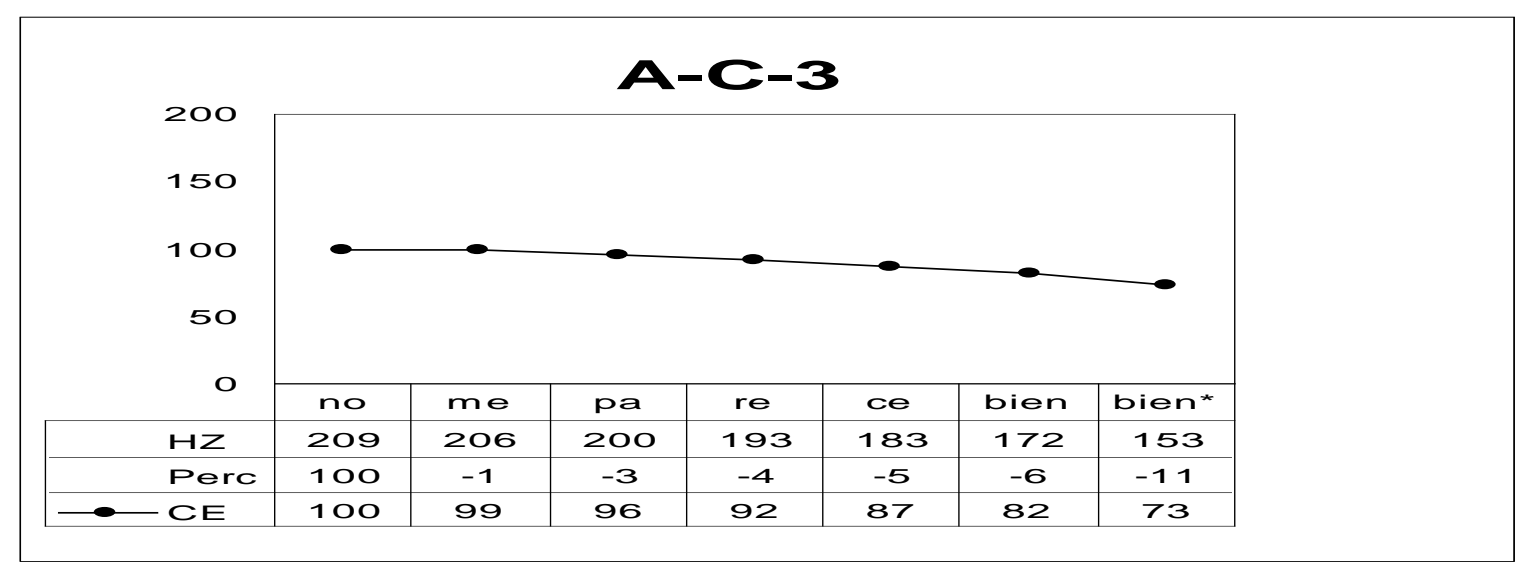

Figura 11. Enunciado original estandarizado de la confrontación "No me parece bien”

La figura 11 muestra el enunciado original relativo a una confrontación.

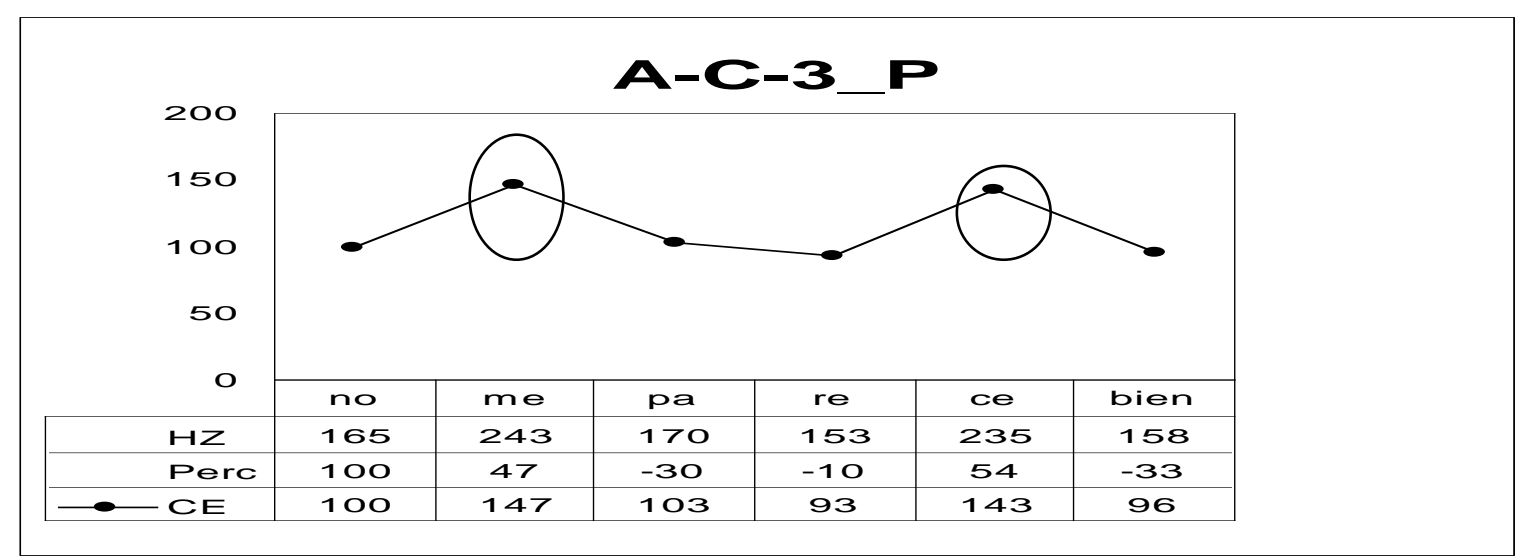

Figura 12. Manipulación del mismo enunciado con prominencias en átonas 
La figura 12 muestra la manipulación del anterior enunciado original. En este caso se ha aumentado solo la F0 de dos segmentos tonales átonos. Como se puede observar en la figura 11 estos mismos segmentos tonales tenían una F0 inferior a la tónica que los precedía.

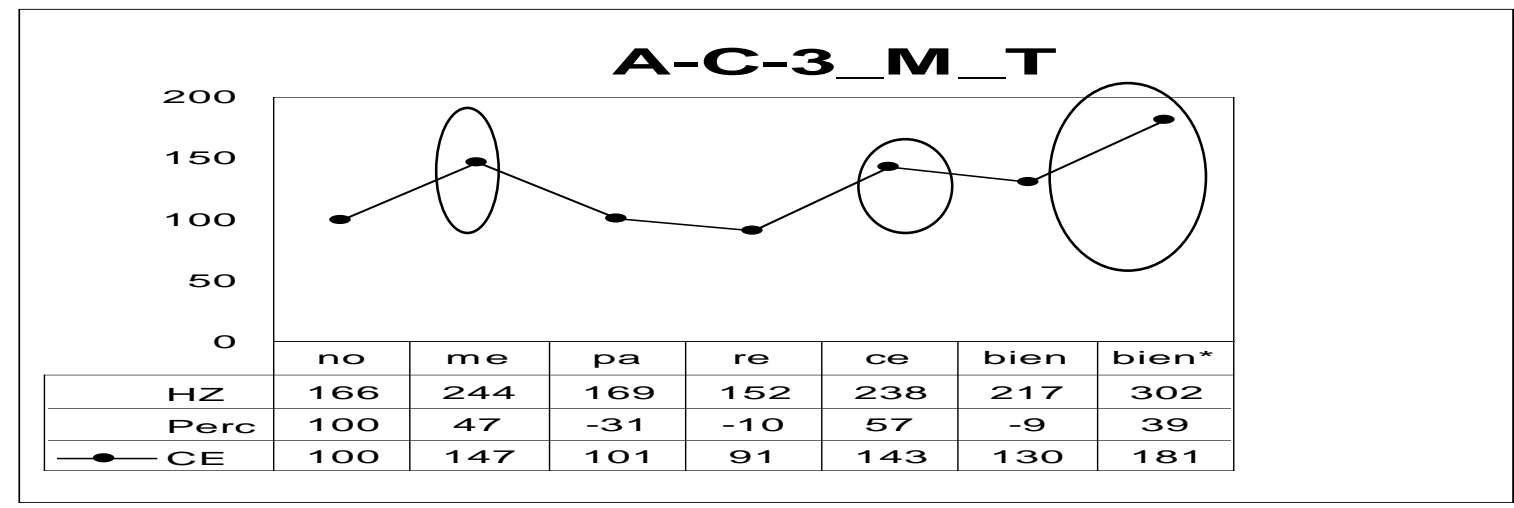

Figura 13. Manipulación del mismo enunciado con prominencias en átonas más inflexión final suspensa

La figura 13 muestra una manipulación combinada del mismo enunciado original. Como se puede observar se han introducido las dos prominencias de los segmentos tonales átonos y una inflexión final suspensa.

Resultados de la fase perceptiva:

Los informantes del experimento (oyentes) determinaron los cambios de significación que aportan las modificaciones de los rasgos melódicos manipulados respondiendo a las siguientes preguntas.

1) para los insultos:

- $\quad$ está enfadado y quiere ofender

- parece que no quiere ofender claramente

2) para las órdenes:

- es una orden dada con autoridad

- más que una orden parece un ruego

3) para las confrontaciones:

- parece que busca la confrontación

- parece que busca la cooperación

Mostramos las tablas con los porcentajes totales de acierto. En los resultados del test se esperaba que los enunciados originales fueran percibidos como descorteses y los manipulados como atenuadores. La tabla siguiente muestra los porcentajes de acierto de los enunciados originales. Como habíamos hipotetizado los insultos, las órdenes y las confrontaciones originales fueron percibidas como tales con altos porcentajes de acierto. 


\begin{tabular}{|c|c|}
\hline CÓDIGOS ORIGINALES & PORCENTAJES DE ACIERTO \\
\hline A-I-1 & $89,6 \%$ \\
\hline P-O-1 & $66,2 \%$ \\
\hline A-C-1 & $78 \%$ \\
\hline P-I-2 & $80,5 \%$ \\
\hline A-O-3 & $70,1 \%$ \\
\hline A-C-5 & $96 \%$ \\
\hline A-I-4 & $83,1 \%$ \\
\hline A-O-4 & $85,7 \%$ \\
\hline P-C-2 & $88,7 \%$ \\
\hline P-I-3 & $79,2 \%$ \\
\hline P-O-2 & $57,1 \%$ \\
\hline A-C-3 & $86 \%$ \\
\hline P-C-4 & $85,1 \%$ \\
\hline P-C-6 & $84,6 \%$ \\
\hline A-C-7 & $88,9 \%$ \\
\hline & \\
\hline
\end{tabular}

En la siguiente tabla observamos los porcentajes de acierto de las manipulaciones simples, es decir con la manipulación de un solo rasgo: IFC corresponde a la manipulación de la inflexión final introduciendo un final circunflejo; IFI igual pero con final interrogativo, con un porcentaje de ascenso superior al 70\%; IFS igual con final suspenso, con un porcentaje de ascenso no superior al 40\%; EP corresponde a las manipulaciones de una sola palabra enfatizándola con una inflexión circunfleja; II corresponde a la manipulación que introducía inflexiones en las vocales internas del enunciado dejando intacta la inflexión final y PA corresponde a la manipulación que modificaba la prominencia de las vocales, en estos casos se eliminaba la prominencia de las tónicas y se introducía en las átonas.

\begin{tabular}{|c|c|}
\hline CÓDIGOS MANIPULACIÓN SIMPLE & PORCENTAJES DE ACIERTO \\
\hline I.F.C & 70,5 \\
\hline I.F.I & 59,4 \\
\hline E.P & 52 \\
\hline I.F.S & 61,4 \\
\hline I.I & 73,8 \\
\hline P.A & 79,9 \\
\hline
\end{tabular}

Como podemos observar en el cuadro anterior, los rasgos melódicos que llevan a percibir el enunciado como más atenuador son: las inflexiones internas y las prominencias en vocales átonas.

\section{CONCLUSIONES}

A partir de la comparación de los dos estudios presentados, los rasgos melódicos corteses del español coloquial (Devís: 2011) y los rasgos melódicos del español hablado por brasileños (Fonseca \& Cantero, 2011) podemos concluir que la percepción que los españoles tienen de los brasileños como personas corteses, afables y simpáticas depende de su entonación prelingüística. Hemos podido observar la coincidencia de dos rasgos melódicos (las inflexiones internas y las prominencias en átonas), responsables de este tipo de percepción. 
De entrada, es un mal entendido que no se percibe como negativo pero pueden darse situaciones contextuales de mayor exigencia y formalidad, como una reunión de negocios, una entrevista de trabajo o una reunión académica, donde sí que podría interpretarse como una entonación inadecuada porque en estos casos podrían interpretarse como hablantes poco comprometidos o poco fiables. La caracterización y comparación de estos rasgos melódicos resulta por tanto de suma importancia para aquellos hablantes brasileños que quieran aprender el español con fines profesionales.

Estos resultados nos hacen pensar en la importancia de trabajar con un método de análisis robusto que combine la extracción de los datos acústicos, estableciendo de forma clara los segmentos tonales; que estandarice los valores absolutos de la F0 en valores relativos ofreciendo una melodía limpia de valores irrelevantes (o "variaciones micromelódicas" y que no olvide validar los resultados mediante pruebas perceptivas. Este es el único camino para colmar progresivamente el vacio temático sobre las funciones pragmáticas del componente melódico $\mathrm{y}$, sobre todo, para llegar a un conocimiento global e integrado de la fenomenología prosódica.

\section{REFERENCIAS BIBLIOGRÁFICAS}

Cantero Serena, Francisco José (1999): “Análisis melódico del habla: principios teóricos y procedimientos”, Actas del I Congreso de Fonética Experimental. Tarragona, 127-133.

Cantero Serena, Francisco José (2002): Teoría y análisis de la entonación. Barcelona: Edicions de la Universitat de Barcelona.

Cantero Serena, Francisco José; Dolors Font-Rotchés (2007): "Entonación del español peninsular en habla espontánea: patrones melódicos y márgenes de dispersión”. Moenia 13, 69-92.

Devís Herraiz, Empar (2011a): “Entonación de (des)cortesía en el español coloquial”, Phonica 7, 36-79.

Fonseca, Aline; Francisco José Cantero Serena (2011): “Características da da entonação do espanhol falado por brasileiros”, en: Actas do VII congresso internacional da ABRALIN. Curitiba (Brasil) 84-98.

Quilis, Antonio (1993): Tratado de fonología y fonética españolas. Madrid, Gredos. 